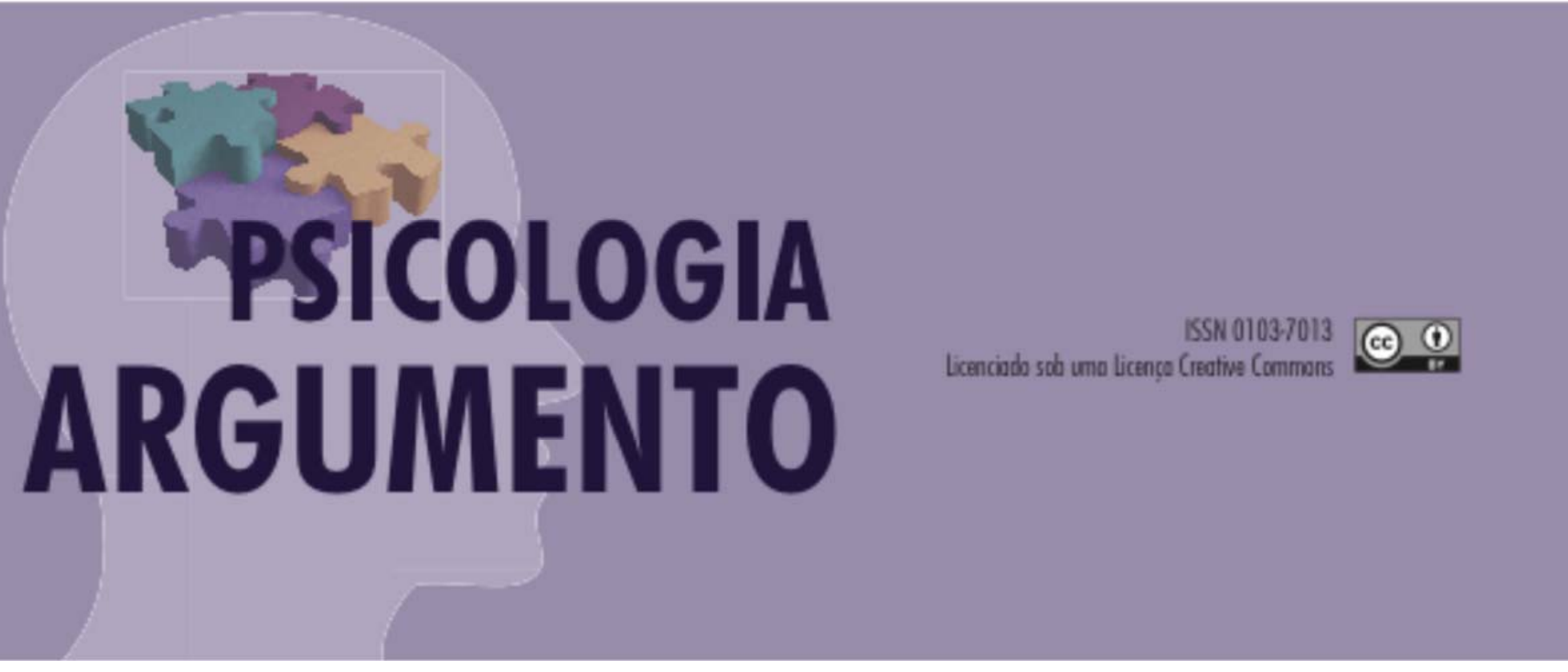

doi: http://dx.doi.org/10.7213/psicolargum.36.91.AO07

\title{
Vergonha e corpo na contemporaneidade: reflexões para a oncologia pediátrica
}

\section{Shame and body in contemporaneity: reflections for pediatric oncology}

\footnotetext{
Milena Dórea de Almeida [a]

[a] Doutora pelo Instituto de Psicologia da Universidade de São Paulo, Professora da Faculdade Metropolitana de Camaçari, Bahia, Brasil. E-mail para contato: milena.dorea@usp.br

Léia Priszkulnik [b]

[b] Professora Doutora do Departamento de Psicologia Clínica do Instituto de Psicologia da Universidade de São Paulo (IPUSP). Docente e orientadora da Graduação e Pós-Graduação do Departamento de Psicologia Clínica do IPUSP. E-mail para contato: leiapris@usp.br
}

\section{Resumo}

O câncer infanto-juvenil é um termo genérico para descrever diferentes malignidades que causam efeitos destrutivos no organismo devido a seu caráter invasivo e metastático, apresentando especificidades diferentes do câncer adulto. Considerando os aspectos emocionais de sobreviver ao câncer pediátrico, destaca-se que há um pequeno número de pesquisas qualitativas que investigam, em profundidade, a vivência do adulto sobrevivente e poucas no campo da Psicanálise. Este trabalho objetiva oferecer subsídios para a formulação de novas modalidades de tratamento pelos profissionais que lidam com pacientes com câncer infanto-juvenil. A concepção de investigação que embasa este trabalho é o modelo de pesquisa qualitativa em psicanálise, cuja preocupação essencial é com o sujeito do inconsciente e com suas vivências e representações singulares. Foram realizadas entrevistas abertas que investigaram os sentidos e significados que adultos, sobreviventes de tumor do sistema nervoso central na infância, atribuem 
às suas experiências de vida durante o adoecimento e após o término do tratamento oncológico; a análise delas assinala que o tema da vergonha aparece como queixa dos entrevistados, e ela norteia as discussões. A vergonha é decorrente de uma timidez excessiva, que leva a um medo exagerado de contato social e afeta o corpo. A psicanálise associa a vergonha à ferida narcísica e este artigo avança sobre as questões contemporâneas do corpo, apresentando discussões e propostas para novas modalidades de tratamento. Essas, ao serem ofertadas pelo psicanalista, podem contribuir para a assistência desses casos no âmbito da saúde pública, tanto nos ambulatórios como nos hospitais.

Palavras-chave: Oncologia Pediátrica; Sobreviventes de Câncer; Vergonha; Corpo; Psicanálise

\begin{abstract}
Childhood cancer is a generic term to describe different malignancies that cause destructive effects on the body due to its invasive and metastatic character, presenting different specificities from adult cancer. Considering the emotional aspects of surviving pediatric cancer, it is important to emphasize that there are a small number of qualitative researches that investigate in depth the experience of the surviving adult and even less in the field of Psychoanalysis. This study aims to offer subsidies for the formulation of new treatment modalities by professionals dealing with childrens and adolescents with cancer. The research concept underlying this work is the qualitative research model in psychoanalysis, whose essential concern is with the subject of the unconscious and with their singular experiences and representations. Open interviews were conducted to investigate the meanings and interpretations that adults, survivors of central nervous system tumors in childhood, attribute to their life experiences during illness and after the end of cancer treatment; their analysis indicates that the shame is a subject that appears as a complaint of the interviewees, and it guides the discussions. Shame is due to excessive shyness, which leads to an exaggerated fear of social contact and affects the body. Psychoanalysis associate shame with narcissistic wound and this article advances on the contemporary definitions of the body, presenting discussions and proposals for new modalities of treatment. These, when offered by the psychoanalyst, can contribute to the assistance of these cases in the field of public health, both in outpatient clinics and in hospitals.
\end{abstract}

Keywords: Pediatric Oncology; Cancer Survivors; Shame; Body; Psychoanalysis

\begin{abstract}
Resumen
El cáncer infanto-juvenil es un término genérico para describir diferentes malignidades que causan efectos destructivos en el organismo debido a su carácter invasivo y metastásico, presentando especificidades diferentes del cáncer adulto. Considerando los aspectos emocionales de sobrevivir al cáncer pediátrico, se destaca que hay un pequeño número de investigaciones cualitativas que investigan, en profundidad, la vivencia del adulto sobreviviente y pocas en el campo del psicoanálisis. Este trabajo tiene como objetivo ofrecer subvenciones para la formulación de nuevas modalidades de tratamiento por los profesionales que tratan de los pacientes con cáncer infanto-juvenil. La concepción de investigación que se basa este trabajo es el modelo de investigación cualitativa en psicoanálisis, cuya preocupación esencial es con el sujeto del inconsciente y con sus vivencias y representaciones singulares. Se realizaron entrevistas abiertas que investigaron los sentidos y significados que los adultos, sobrevivientes del tumor del sistema nervioso central en la infancia, atribuyen a sus experiencias de vida durante la enfermedad y después del término del tratamiento oncológico; el análisis de ellos señala que el tema de la vergüenza aparece como queja de los entrevistados, y ella orienta las discusiones. La vergüenza es consecuencia de una timidez excesiva, que lleva a un miedo exagerado de contacto social y afecta al cuerpo. El
\end{abstract}


psicoanálisis asocia la vergüenza a la herida narcisista y este artículo avanza sobre las cuestiones contemporáneas del cuerpo, presentando discusiones y propuestas para nuevas modalidades de tratamiento. Esas, al ser ofrecidas por el psicoanalista, pueden contribuir a la asistencia de esos casos en el ámbito de la salud pública, tanto en los ambulatorios como en los hospitales.

Palabras clave: Oncología Pediátrica; Supervivientes de Cáncer; la vergüenza; el cuerpo; Psicoanálisis.

\section{INTRODUÇÃO}

O câncer infanto-juvenil é um termo genérico para descrever diferentes malignidades que causam efeitos destrutivos no organismo devido a seu caráter invasivo e metastático, apresentando especificidades diferentes do câncer adulto. Considerando os aspectos emocionais de sobreviver ao câncer, destaca-se que há um pequeno número de pesquisas de cunho qualitativo quando comparadas às de metodologia quantitativa, que, apesar de oferecerem uma compreensão ampla e multidimensional da situação emocional dos sobreviventes, não investigam, em profundidade, a vivência do adulto sobrevivente de câncer pediátrico. Além disso, a literatura nacional apresenta poucas publicações de pesquisas em Psicanálise que considerem esses sujeitos. Ser sobrevivente de câncer infanto-juvenil envolve aspectos orgânicos, sociais, culturais e psíquicos, e o interesse por esse tipo de pesquisa se torna crescente em virtude da necessidade de conhecer os efeitos secundários do tratamento oncológico, aperfeiçoar a assistência em oncologia pediátrica e melhorar a qualidade de vida dos pacientes.

Este trabalho tem como objetivo oferecer subsídios para a formulação de novas modalidades de tratamento pelos profissionais que lidam com pacientes com câncer infanto-juvenil. Tendo claro que as doenças podem se repetir nas pessoas, mas o sofrimento não, foram realizadas entrevistas, orientadas pela psicanálise freud-lacaniana, que buscaram investigar os sentidos e significados que os adultos, sobreviventes de tumor do sistema nervoso central (SNC) na infância, atribuem às suas experiências de vida durante o adoecimento e após o término do tratamento oncológico. A criança com câncer vivencia a morte de outras crianças, a possibilidade de sua própria morte, as transformações no seu corpo, a dor física, as privações sociais, percebe a fragilidade e o sofrimento de seus pais e adota, muitas vezes, comportamentos para protegê-los. O fim do tratamento não necessariamente afasta essas vivências. A partir das reflexões suscitadas pela análise das entrevistas, a vergonha surgiu como queixa desses pacientes. Neste texto, esse tema vai nortear as discussões e as propostas para as novas modalidades de tratamento.

O psicanalista que atua em instituições de saúde, também, pode levar em conta o sujeito do inconsciente, o sujeito que sabe do seu sofrimento, apresentase na sua singularidade, com sua história e experiências, e se mostra refratário às 
medidas gerais e homogêneas. Convém enfatizar que o sofrimento não tem uma manifestação única para todos os indivíduos de uma mesma família, mesma cultura ou mesmo período histórico, pois o que é sofrimento para um, pode não ser para outro, mesmo quando submetidos às mesmas condições adversas. Embora o psicanalista reconheça a intensidade de muitas das vivências dos sobreviventes de câncer, os recursos teóricos da Psicanálise apontam que muitas questões não são patológicas e dizem respeito a um mal-estar relacionado às vicissitudes da contemporaneidade.

É importante, também, trazer as narrativas desse público, já que ele se torna crescente na atualidade em virtude do sucesso no tratamento oncológico. Dados europeus recentes indicam que um em cada 750 jovens adultos é sobrevivente de câncer infanto-juvenil (Brown et al, 2015). No Brasil, não há dados estatísticos que sintetizem esse índice. Em relação à taxa de cura, Teresa Fonseca, presidente da Sociedade Brasileira de Oncologia Pediátrica (SOBOPE), informa que em torno de $70 \%$ dos cânceres pediátricos são curados, quando são diagnosticados precocemente e tratados em centros especializados (Verdélio, 2016). Assim, tornase importante inserir os pacientes oncológicos nas discussões acerca do mal-estar contemporâneo, pois eles estão compartilhando da vida, logo a história da doença não é a única referência identificatória e os profissionais que lidam com eles precisam apreender suas queixas em relação ao contexto social, cultural e econômico em que estão vivendo.

O significado da palavra "contemporâneo" adotado no Dicionário Online de Português é: como substantivo masculino - algo ou alguém que fez parte de uma mesma época ou que faz parte do presente (tempo atual); como adjetivo - que se pode referir ao período que, convencionalmente, teve seu início com a Revolução Francesa (“Contemporâneo", c2009 - 2018). A contemporaneidade é um conceito eminentemente temporal. Psicanalistas, tomando como base a própria psicanálise e outros campos do saber, como as ciências sociais, a filosofia e a antropologia, discutem o conceito.

Birman (2014) destaca que a contemporaneidade é marcada pelo acirramento dos processos de globalização e pelo avanço da economia neoliberal, que tem como efeito a redução do Estado Soberano e, consequentemente, o esvaziamento das instâncias mediadoras, o que favorece o desamparo do homem. Magalhães e Azevedo (2016) assinalam que na contemporaneidade, os ideais, as tradições, a autoridade paterna e as religiões perderam sua importância, favorecendo que os sujeitos criem maneiras diversas de se posicionar diante das solicitações e mudanças dos contextos social, econômico e cultural. Dunker (2015) acrescenta que, na contemporaneidade, há o desenvolvimento de técnicas modernas, em Biologia, em Genética e na Medicina em geral, que vem transformando em profundidade as questões relativas à relação do sujeito com seu próprio corpo, com o outro e com a cultura.

Portanto, essas características do mundo pós-moderno refletem na cultura, na economia, na forma de viver e de se relacionar e que implicam também em mudanças na subjetividade, tornando as questões atuais do sujeito distintas daquelas que os sujeitos apresentavam na origem da Psicanálise, sendo a 
vergonha de si uma das principais queixas presentes na clínica psicanalítica contemporânea (Venturi \& Verztman, 2012). A vergonha de si é definida como uma emoção caracterizada por uma timidez excessiva que leva a um medo exagerado de contato com os outros, estando articulada à categoria nosológica de Fobia Social, conforme descrita nos manuais de psiquiatria. Nesse sentido, a premissa principal deste trabalho é que, nos sujeitos pesquisados, a vergonha representa um sofrimento social e psíquico, podendo se somar aos prejuízos dos efeitos tardios do câncer e do tratamento oncológico, influenciando diferentes áreas da vida do sujeito, como desempenho escolar, atividades laborais e vínculos sociais.

\section{MÉTODO}

A concepção de investigação que embasa este trabalho é o modelo de pesquisa qualitativa em Psicanálise, que visa conhecer em profundidade as vivências singulares dos sujeitos e que representações eles têm dessas experiências de vida. Assim, a preocupação essencial é com o sujeito do inconsciente e não lida com o saber universal e genérico da ciência clássica (Elia, 2000). Este estudo foi dividido em pesquisa bibliográfica e pesquisa de campo. $O$ local da pesquisa de campo foi o Hospital São Rafael - Unidade ONCO, localizado na cidade de Salvador / BA.

$\mathrm{Na}$ pesquisa de campo, foram realizadas entrevistas clínicas como instrumento para a coleta de dados, sendo consideradas adequadas para a investigação psicanalítica, já que buscam conhecer os processos mentais inconscientes subjacentes às experiências vividas. Portanto, os princípios freudianos fundamentais estão presentes: o saber do inconsciente, a associação livre, a atenção uniformemente flutuante e a transferência, não sendo esses impedidos de serem instalados no contexto guiado pelo interesse da pesquisa (Elia, 2000). Na entrevista para a pesquisa psicanalítica, o método é a "escuta como testemunho e resgate de memória", considerando que a narrativa produzida pelo sujeito na entrevista se organiza a partir da relação transferencial com o pesquisador (Rosa, 2004, p, 344).

A relação transferencial entrevistador-entrevistado implica que cada um ocupe lugares que, sendo utilizado de forma estratégica pelo psicanalista, permite que o sujeito fale, possa se escutar e se apropriar do seu discurso (Rosa, 2004). Portanto, o relato que interessa nesse setting da entrevista é o elemento novo, que supera o discurso da consciência. Para tanto, o pesquisador-psicanalista precisa de sua formação contínua, que inclui a análise pessoal.

\subsection{PROCEDIMENTO DE COLETA DE DADOS}

Incialmente, foram lidos os prontuários dos pacientes com diagnóstico de tumor de SNC e organizada uma lista com todos aqueles que se adequavam ao estudo: 
- Critérios de inclusão: adultos, entre 20 e 59 anos, que tiveram tumor de SNC na infância e com tempo fora de tratamento oncológico de, no mínimo, cinco anos.

- Critério de Exclusão: os que apresentaram, no período de realização das entrevistas, ou suspeita ou evidência de doença oncológica.

Foram realizados contatos telefônicos e combinado o dia para a entrevista, quando o Termo de Consentimento Livre e Esclarecido foi lido e assinado pelo paciente em duas vias, autorizando sua participação voluntária. Todos os contatados aceitaram participar do estudo.

As entrevistas foram fundamentadas em uma questão disparadora, para introduzir o tema principal:

- O que você se lembra da época do diagnóstico e do tratamento?

Perguntas adicionais foram feitas para aprofundar os aspectos relevantes ao tema em estudo, tendo como guia os objetivos da pesquisa e a fala do entrevistado. As entrevistas foram individuais, gravadas em aparelho digital e, posteriormente, transcritas para documentos de computador. Após isso, as gravações foram apagadas. O uso do gravador permitiu à pesquisadora liberdade para prestar atenção à fala do entrevistado e a suas intervenções, priorizando o contexto da entrevista.

Para fechar a amostra, foi adotado o critério da saturação teórica, cujas entrevistas foram interrompidas quando as respostas de novos sujeitos passaram a apresentar uma quantidade de repetições em seu conteúdo e este já apresentava elementos suficientes e necessários para atingir os objetivos propostos. Já para a realização de outra entrevista com o mesmo sujeito, adotou-se os critérios: coletar mais dados, aprofundar assuntos abordados no encontro anterior, tratar de temas que passaram despercebidos pela entrevistadora. E mais, questões de ordem prática, como possibilidade de acesso ao paciente e tempo disponível para a realização da pesquisa.

Participaram da pesquisa onze sujeitos: oito participaram de uma entrevista e três tiveram dois encontros, totalizando quatorze entrevistas.

\subsection{A ANÁLISE DOS DADOS}

O material transcrito foi lido, repetidas vezes, com o objetivo de perceber os pontos importantes das entrevistas. Posteriormente, realizou-se a categorização e subcategorização do material em grupos de temas, a partir de sua repetição ou relevância que permitissem estudar as narrativas dos sobreviventes em profundidade. A análise dos resultados foi orientada pelo referencial psicanalítico freud-lacaniano.

\subsection{CONSIDERAÇÕES ÉTICAS}


Este estudo foi aprovado pelo Comitê de Ética de Pesquisa com Seres Humanos do Monte Tabor - Hospital São Rafael e do Instituto de Psicologia da Universidade de São Paulo. Os participantes e as pessoas citadas por eles são identificados por nomes fictícios, escolhidos aleatoriamente pela própria pesquisadora, preservando suas identidades.

\section{RESULTADOS E DISCUSSÃO}

Nas entrevistas realizadas, a vergonha aparece como queixa associada a:

- Medo de comunicar, aos outros, seu histórico de tratamento cerebral e suas dificuldades intelectuais e motoras decorrentes da doença e do tratamento oncológico;

- Sensação de estar sempre sendo olhado pelas pessoas;

- Dificuldade de encarar o olhar dos outros na rua;

- Receio de parecer inadequado e de dizer tolices;

- Timidez excessiva em se expressar para pessoas desconhecidas (exemplo: pedir um suco em uma lanchonete) e;

- Julgamento de inadequação por questionar se a morte seria uma saída favorável às suas dificuldades da vida atual.

Sem desconsiderar que os efeitos tardios do tratamento podem interferir nos relatos e no contato social que os sobreviventes de tumores cerebrais estabelecem, deve-se também ponderar que as situações vivenciadas como vergonhosas vêm acompanhadas por sintomas como palpitação, rubor, tremor, tensão muscular e sudorese, podendo intensificar os sintomas dos efeitos tardios neurocognitivos do tratamento oncológico. É importante também lembrar que toda queixa que diz respeito a um sofrimento emocional deve ser valorizada e investigada, sem prejulgamentos referentes a dados estatísticos sobre a prevalência dos efeitos tardios, pois, em Psicanálise, o que importa são as repercussões dos efeitos tardios na vida do sujeito.

Nas discussão, foram realizados recortes nas falas, sendo apresentadas algumas vinhetas consideradas significativas para ilustrar as reflexões. Essas vinhetas funcionam como um caso clínico que, ao ser exposto, tem a finalidade de ajudar o leitor a avançar no estudo teórico e contribuir para o profissionalpsicanalista defender sua ética e construir dispositivos clínicos para ajudar os sujeitos atendidos. A ética da psicanálise é uma ética do singular, das respostas de cada sujeito para os enigmas de sua existência. Não existe a proposta de um caminho único e necessário, mas algo que se descobre em cada caso, isso para evitar que o particular de cada experiência se perca no universal de soluções gerais, já que não existem soluções que sejam boas para todos. A escuta psicanalítica abre uma brecha para que os próprios sujeitos, os mais interessados, sejam ouvidos e eles próprios possam vir a criar soluções. O profissional não as sabe de antemão, mas procura estar junto no percurso singular de construção de cada resposta. 


\subsection{A VERGONHA NAS SOCIEDADES OCIDENTAIS E NA CLÍNICA PSICANALÍTICA CONTEMPORÂNEA}

A vergonha não é tema de destaque nas obras da psicanálise freudiana. "Freud, por exemplo, não dedicou sequer um artigo exclusivamente a essa noção. Não é possível circunscrever em sua obra um conceito de vergonha, ao contrário do que ocorre com a culpa" (Venturi \& Verztman, 2012, p. 135).

Assim, para iniciar suas reflexões sobre a vergonha nas sociedades ocidentais, esses autores e Calligaris (2006) tomam como referência a obra da antropóloga americana Ruth Benedict denominada "O crisântemo e a espada", de 1946, publicada imediatamente após a Segunda Guerra Mundial. Essa autora conclui que, em cada tipo de sociedade, o comportamento moral é regulado ou pela vergonha (por exemplo, no Japão e em outros períodos históricos no Ocidente) ou pela culpa (por exemplo, as sociedades ocidentais modernas). Ressalta-se que ambos os afetos podem estar presentes nas sociedades, porém um deles é o dominante.

Ao escrever sobre o sofrimento neurótico na Europa Ocidental do início do século XX, Freud, em sua obra, destaca o conflito entre o proibido e o permitido, em que a culpa é causada pela transgressão da lei de proibição (Farah, 2012). Na culpa, as instâncias de avaliação moral são internalizadas pelo sujeito, não necessitando do olhar do outro reprovador. O sujeito toma como referência uma lei abstrata, e quanto maior for o rigor dessa lei, maior será o sofrimento, independentemente de quem testemunha o ato transgressivo (Venturi \& Verztman, 2012). Trata-se, portanto, de uma emoção privada, experimentada solitariamente, típica de uma cultura individualista. A reparação da culpa pode ocorrer pelo arrependimento, pela confissão do ato transgressivo e pelo sofrimento decorrente da culpa.

Em relação à vergonha, os autores escrevem que, em sociedades tradicionais, as instâncias de avaliação moral são externas ao sujeito, que precisa do olhar julgador e acusador de outra pessoa (real ou fantasiada) para que a vergonha emerja. Esse sentimento está ligado a ideais e a valores relacionados à honra, e a punição moral diante do ato transgressivo advém do rebaixamento da imagem do sujeito diante de um determinado ideal constituído a partir do olhar daqueles que presenciam o ato. Portanto, a vergonha não emerge imediatamente após o ato vexatório, mas sim com a exposição pública desse ato e sua intensidade é proporcional ao valor dado à testemunha.

Então, nas sociedades tradicionais, a vergonha é predominantemente pública, regulada pelos códigos de honra, pela fidelidade ao legado dos ancestrais e pelo sentimento de pertencimento a uma casta, mancha a dignidade e a imagem de si e não pode ser reparada nem por arrependimento nem por confissão nem por sofrimento.

Embora Calligaris (2006) concorde com esta diferenciação realizada por Benedict, ele identifica nas sociedades ocidentais modernas, sobretudo de tradição judaico-cristã, como o Brasil, que a vergonha exerce um importante papel na 
regulação da ação moral. A culpa é um péssimo regulador moral, pois o sofrimento decorrente do sentimento de culpa funciona como uma espécie de pagamento que permite $o$ ato transgressivo e absolve o sujeito culpado. Em contraposição, a vergonha é um regulador moral muito mais eficaz, já que o sofrimento não restitui a dignidade do sujeito. Ditos populares brasileiros, como "não tem vergonha na cara", "sem-vergonha" e "cara-de-pau", indicam que, na sabedoria do senso comum, a vergonha é mais moralizadora que a culpa.

Porém, faz-se necessário uma consideração: a vergonha, que emerge como queixa e sofrimento na clínica psicanalítica na atualidade, não se refere à ferida da honra nem ao risco de contradizer aos ideais públicos partilhados, conforme identificado nas sociedades não-ocidentais e de outros períodos históricos do Ocidente. A vergonha de hoje é associada a um déficit no desempenho individual que assume para o sujeito o caráter de uma marca que ameaça sua identidade e suas relações com seu próprio corpo, com o outro e com a cultura. Trata-se da vergonha de se sentir insuficiente:

Um aspecto relevante a ser notado nesse contexto é a importância do desempenho individual para a ocorrência da vergonha. Este sentimento surge, nesses sujeitos, acompanhado de uma profunda sensação de insuficiência e inadequação diante do outro. Este deixa de ser confiável; passa a ser hostil, um avaliador quase persecutório. O que está em jogo não remete à desonra ou ao desrespeito a um valor coletivo. Não há qualquer valor dessa ordem a defender, nenhum nome a honrar, nenhum futuro a construir. Trata-se muito mais de um déficit da performance individual sem qualquer ligação com valores que poderíamos qualificar como ético-morais. (Venturi \& Vertzman, 2012, p. 132)

A vergonha é despertada quando um ato expõe a fragilidade do sujeito, que não atinge ao ideal naquilo que ele gostaria de fazer ou ser. Um ato que, para o sujeito, evidencia a diferença da imagem que ele busca assumir frente ao grupo, ameaçando a identidade e as relações sociais dele. Este sentimento de insuficiência diante de um ideal para si mesmo aponta para a natureza narcísica da vergonha e a particulariza para a vergonha de si.

Os autores citados acima relativizam o sofrimento psíquico de acordo com a intensidade da vergonha, havendo duas grandes categorias que demandam ajuda dos profissionais do campo psi: os sujeitos que vivenciam a vergonha de si como um embaraço constante em suas ações e aqueles que a vivenciam como uma humilhação que os paralisa.

Os sujeitos da primeira categoria são considerados menos grave de um ponto de vista clínico, pois ainda é possível ter recursos interno e externo de elaboração para lidar com a sensação de exposição constante, mesmo que estes mecanismos de proteção sejam ou a fuga ou o evitamento. Já nos segundos, a forte humilhação e o rebaixamento da imagem de si que sentem contribuem para internalização dos valores humilhantes, que passam a constituir a identidade do 
sujeito. Com sua identidade violada, esses sujeitos dispõem de poucos recursos ou nenhum - para lidar com as situações de contato social. Esses sujeitos que não conseguem construir uma identidade para si apontam para a ferida narcísica e para ausência de um posicionamento diante dos investimentos em si mesmo (PachecoFerreira, 2012).

Contextualizando essas reflexões, acrescenta-se que os sobreviventes de tumor de SNC, por terem se ausentado da escola e diminuído o contato social com os amigos, durante o tratamento oncológico, podem apresentar, no retorno às atividades, menores estratégias de relacionamento, influenciando na sensação de vergonha e de exclusão. Além dessa ponderação, vale questionar quais os elementos que estariam envolvidos na vergonha deles: a ferida narcísica seria ocasionada pelo câncer, pelo tratamento, pelos efeitos tardios aparentes ou pelas exigências da sociedade contemporânea.

\subsubsection{Contribuições psicanalíticas sobre a ferida narcísica}

O tema do narcisismo adquire o valor de um conceito no texto "Sobre o narcisismo: uma introdução" (Freud, 1914/1996), sendo definido como um estado precoce em que a criança redireciona o investimento libidinal para o próprio Eu, tomando a si mesmo como objeto de amor e desinvestindo os objetos do mundo externo (Laplanche \& Pontalis, 2001).

A primeira experiência narcísica do sujeito ocorre quando ele capta a imagem de si, decorrente do estádio do espelho e, somadas a outras experiências em que a criança se percebe como centro e âmago da cena, funda o narcisismo primário (Lacan, 1998). A representação narcísica primária é a imagem da criança maravilhosa, perfeita e completa, que precisa ser abandonada para que o Eu possa se desenvolver (Leclaire, 1977). Porém, esse abandono nunca é completo, conservando-a sobre outras formas. No lugar deste narcisismo se constituirá o Eu Ideal - substituto direto do narcisismo primário e representado pelas aspirações e sonhos de ser possuído de toda perfeição de valor como acha ter sido outrora, na primeira infância - e o Ideal do Eu - modelo de referência para o sujeito, produto da influência crítica das figuras parentais e de seus substitutos sociais e do agente psíquico auto-observador (Freud, 1914/1996). A partir daí, o sujeito vive uma espécie de movimento de gangorra entre o investimento libidinal no $\mathrm{Eu}$ e o investimento libidinal no objeto, em que o enriquecimento em um, empobrece o outro.

Ao identificar a vergonha como uma ferida narcísica, afirma-se que esta não se passa na relação de si consigo. "Há sempre a pressuposição de um outro, que percebe, de alguma maneira, algo que não é para ser visto" (Venturi \& Verztman, 2012, p. 138). O olhar que julga testemunha uma decadência social, sendo a vergonha derivada de uma exposição pública de uma infelicidade privada que simboliza a destituição do sujeito de sua comunidade (Zygouris, 1988/1995).

O que o sujeito expõe e que não era para tornar público é quando ele vivencia situações que afetam especificamente o Eu Ideal e o Ideal do Eu, projetando uma 
sombra sobre a identidade do sujeito e instaurando uma separação entre o sujeito e o grupo. E, devido a esses abalos, a vergonha se associa à angústia, sendo vivenciada também como momentos desorientadores, de desamparo e de impotência.

Os entrevistados da pesquisa relatam que um dos maiores sofrimentos no retorno às atividades sociais e escolares é perceber, através das experiências, que exibem as limitações provocadas pelas sequelas, que antes do adoecimento era uma criança "perfeita", "brincava sem limites", "nunca perdia de ano" e agora enfrenta dificuldades motoras e cognitivas. Isso indica a idealização imaginária do Eu que pode intensificar o sentimento de impotência.

A entrevistada Aurora refere, com frequência e demonstrando pesar, uma cena: no retorno à escola, a professora apagava o quadro antes de ela terminar de copiar em seu caderno e, por isso, desistiu de estudar. Quando questionada se ela escreve em casa, mesmo que seja para ninguém ler, ela responde que sente vergonha, pois demora em escrever e sua letra está feia. No aguardo em "ficar boa", ela passa os dias no quarto e só sai de casa se for apoiada no ombro da mãe e para ir a consultas e tratamento fisioterápico. "O que me mata é a vergonha", conclui para justificar sua ausência de contatos sociais. Seu testemunho é o que mais contribui nas reflexões acerca da vergonha. Escutá-la traz a sensação de que ela está todo tempo sendo atravessada pelo olhar externo julgador. Como se o outro fosse capaz de diagnosticar imediatamente suas falhas e a julgar negativamente por elas.

Do ponto de vista do sujeito envergonhado, este seu aspecto destoa do ideal supostamente compartilhado pelo grupo. Não se trata necessariamente de algo ruim ou criticável. Basta que essa característica ou atitude seja peculiar ao sujeito para que o transforme em um estranho e o posicione a uma distância importante dos outros membros do agrupamento em questão. Nesse tipo de vergonha, essa idiossincrasia, que situa o sujeito como um não-semelhante no seio de um determinado grupo, assume o posto de marca identificatória mais significativa e passa a representar a identidade como um todo. (Venturi \& Vertzman, 2012, p. 138)

Ou seja, o envergonhado fantasia que é mal visto pelo outro, que toda sua identidade foi afetada, e se resume por esta característica que ele considera desviante do grupo. Há uma projeção de seu julgamento no olhar do outro. "Eles vão pensar o quê de mim? Que eu sou louca!", esta é a fala de Aurora quando explica sua dificuldade em sair de casa e perceber o olhar das pessoas na rua. Maria também relata esse julgamento reprovador que subentende ser do outro, ao relatar que não gosta de comentar sobre seu adoecimento e seus efeitos tardios, para evitar associações sobre "quem tem problema na cabeça tem distúrbio". A vergonha existe porque o sujeito estabeleceu sua noção de bem e de mal, de verdadeiro e de falso e do direito ao segredo. Porém, ter direito ao segredo é 
prerrogativa dos que possuem fronteiras narcísicas bem definidas, não se sentindo transparentes ao olhar do outro (Pacheco-Ferreira, 2012).

Zygouris (1988/1995) denuncia a violência característica da vergonha: violência feita ao psiquismo e inscrita no próprio corpo, como uma experiência traumática. Nelson revela que em todo colégio que vai, chora, antecipadamente, perguntando-se: "Será que as pessoas vão me aceitar?" e aguarda que, "de repente", melhore das sequelas motoras "pra poder ter mais dignidade", como por exemplo, não precisar de ninguém para sair de casa. Essa sensação da ausência de dignidade exemplifica essa violência psíquica.

Ao caráter violento, acrescenta-se o fato de a vergonha ser dificilmente esquecida e da impossibilidade de dar uma resposta eficiente à situação vergonhosa (Zygouris, 1988/1995). A vergonha não é esquecida nem transformada, ela é conservada intacta, como toda experiência traumática. O envergonhado fica paralisado, não consegue reagir. Daí, o relato constante de uma mesma cena e um posicionamento passivo identificado nos entrevistados. Por exemplo, quando questionado quais planos Nelson faz para sua vida futura, ele responde: "Planos? Planos? Não [risada]. Não, não faço planos nenhum, porque tá tudo bagunçado".

O tratamento da vergonha e o trabalho de luto podem coincidir. Nelson fala do processo doloroso de matar um sonho, para depois, reconstruir novas formas de viver, e isso constitui um trabalho de luto, que precisa ser feito para que o desejo do sujeito possa advir. Esse não reconhecimento da perda pode se apresentar como uma impossibilidade do sujeito se perceber e se sentir como um suporte de narrativas positivas, sentindo-se impotente através das "narrativas por subtração: eu não sou; eu não posso; eu não sei; eu não desejo; eu não quero; eu não penso e assim por diante". (Costa, 2012, p. 12)

Retomando o foco no tema, a crueldade da vergonha depende da intensidade da situação vexatória e, também, varia conforme o modo de constituição do narcisismo e da capacidade de reorganização psíquica (Venturi \& Verszman, 2012). O que indica que o outro interfere na vergonha, não somente pela crença na certeza de seu mau julgamento, mas também pela sua capacidade de oferecer recursos para proteção do envergonhado.

Ao refletir sobre a importância do meio social no estabelecimento da vergonha e de sua reparação, questiona-se: quais elementos são acrescidos ao sofrimento psíquico da vergonha? Para Farah (2012), a partir da década de 1970, ideais de iniciativa, autonomia e independência passam a ser valorizados para a responsabilização do sujeito pelo seu próprio destino e quem não manifesta essas qualidades se sente insuficiente. Então, além dos déficits e limitações que os sobreviventes já sofrem, há o padrão da contemporaneidade que influencia no rígido julgamento.

\subsubsection{Reflexões sobre a contemporaneidade}


Os sobreviventes entrevistados relatam momentos em que sofreram preconceito nos grupos de amigos devido sua aparência diferente, tal como, estarem careca, terem a cicatriz na cabeça ou apresentarem lentidão nas atividades. Também se sentem cobrados para realizarem determinada ação que não é mais possível devido às sequelas, além de relatarem que a maioria das pessoas tem falta de paciência em acompanhar suas falas e se recusam a falar devagar para que eles possam acompanhar. Essa exigência está de acordo com o padrão contemporâneo do corpo perfeito, que a maioria das pessoas está submetida. Na sociedade contemporânea, o corpo é concebido como "uma máquina maravilhosa que pode ser manipulada, moldada, dominada. Um corpo sem limites, no qual a razão pode exercer seu poderio. Um corpo objetivado, desconsiderando que é um corpo em que o sujeito humano se suporta" (Priszkulnik, 2011, p. 157). Consoante a isso, Fernandes (2011) escreve:

O corpo está em alta! Alta cotação, alta produção, alto investimento... alta frustração. Alvo do ideal de completude e perfeição, veiculado na pós-modernidade, o corpo parece servir de forma privilegiada, por intermédio da valorização da magreza, da boa forma e da saúde perfeita, como estandarte de uma época marcada pela linearidade anestesiada dos ideais. (p. 15)

Esse superinvestimento no corpo acaba por acarretar em grande frustração e sofrimento verificado nos novos sintomas que adentram os atendimentos dos psicanalistas.

Assiste-se, assim, à emergência dos ditos "novos sintomas": os abundantes e variados transtornos alimentares, a compulsão para trabalhar, para fazer exercícios físicos, as incessantes intervenções cirúrgicas de modelagem do corpo, a sexualidade compulsiva, o horror do envelhecimento, a exigência da ação, o terror da passividade, a busca psicopatológica da saúde ou, ao contrário, um esquecimento patológico do corpo, e ainda a variedade dos quadros de somatização. Sintomas que denotam, a meu ver, de forma positiva ou negativa, a submissão completa do corpo. (Fernandes, 2011, p. 19)

Essas características são incluídas no que se denomina Sociedade do Espetáculo, marcada pelas condições modernas de produção e de consumo e caracterizada pela cultura das aparências, onde as pessoas não buscam ser algo, mas parecer que são e ter algo (Debord, 2002). Assim, as relações sociais entre as pessoas são mediatizadas pela imagem, a exterioridade é valorizada e os conflitos internos são camuflados. O resultado disso é a produção de uma alienação na imagem, daí o caráter narcísico da cultura atual, onde o sujeito está, constantemente, observando-se e se julgando (Dunker, 2016). Para trazer uma ilustração entre os entrevistados, Aurora refere que todo aniversário que faz, 
compara-se às amigas de mesma idade, sentindo-se aquém delas, pois não faz nada, enquanto suas amigas já concluíram os estudos e trabalham, contribuindo no sustento da casa.

Nesta concepção de sociedade, o próprio sujeito é o responsável pelo que Ihe acontece e o seu valor está agregado a sua capacidade de fazer e produzir. Relacionado a isso, alguns sobreviventes classificam suas dificuldades como ocasionadas por "distração" ou "pouca atenção", exemplificando esse viés da responsabilização. Os psicanalistas precisam ter conhecimento sobre os padrões dessa sociedade para saber como coloca-los em dúvida, pois não há como negar a influência das concepções sociais na subjetividade, mas podem-se ofertar intervenções que convoquem o sujeito a construir novos sentidos e significados para as exigências e a modificar o seu próprio olhar para as alterações corporais que suscitam estranheza por não se adequar aos padrões da contemporaneidade.

\subsection{CONSIDERAÇÕES SOBRE NOVAS MODALIDADES DE} TRATAMENTO

A partir da investigação que valoriza a subjetividade de cada paciente entrevistado, verifica-se o sofrimento psíquico como um dos efeitos tardios do câncer infanto-juvenil que precisa ser considerado no momento do planejamento de novas modalidades de tratamento e sublinha-se que o sofrimento da criança e do adolescente quando não reconhecido tem implicações importantes no trabalho de elaboração da experiência vivida. Para a psicanálise, a clínica é sempre a clínica do sujeito e não da doença.

O psicanalista pode ofertar novas modalidades de tratamento que proporcionem condições para que o sujeito fale sobre seu sofrimento, seja escutado por um outro e se escute, buscando construir novos sentidos e significados para sua história e para os desafios que as vicissitudes contemporâneas proporcionam. O que qualifica uma experiência analítica é o seu modo peculiar de escuta, tendo como instrumento a fala do paciente e como operador clínico a transferência. Assim, através de uma prática de cuidado, a psicanálise possibilita uma restauração subjetiva, implicando o sujeito, não apenas naquilo que the provoca vergonha, mas também na construção de recursos interno e externo para lidar, de forma menos sofrida, com as situações que trazem a sensação de exposição.

Considerando a atuação do psicanalista na oncologia pediátrica, esse espaço pode ser construído a partir de entrevistas de acolhimento em diferentes momentos do tratamento, como por exemplo, na admissão do paciente na instituição, antes de procedimentos invasivos, antes e depois do tratamento, nas consultas de acompanhamento após o término da terapia oncológica.

Defende-se que essas entrevistas tenham o sentido de prevenção e não sejam realizadas somente quando algo emerge e prejudica o trabalho da equipe médica e paramédica (Almeida, 2017). A função dessas entrevistas iniciais de acolhimento é de apostar na construção de uma narrativa implicada na história 
subjetiva do sujeito, a partir da relação transferencial com o psicanalista, que precisa estar atento a situações ou dramas familiares e deixar uma abertura para que a demanda apareça e a pessoa tenha liberdade de procurar o psicanalista sempre que sentir necessidade. Portanto, pensa-se em entrevistas periódicas, porém a quantidade e quais pessoas participarão dessas entrevistas serão variáveis, avaliadas de acordo com cada caso e sem a necessidade de ter a continuidade de um processo psicanalítico.

Alguns entrevistados revelaram para a pesquisadora a importância de terem participado das entrevistas. Nelson avalia que foi "muito bom, porque eu pude expressar o que eu não tenho expressado direito, entendeu? Foi muito bom porque certas pessoas, porque se eu falasse assim, algumas coisas, certas pessoas não iam compreender, entendeu, não iam compreender muito". Marcone refere que foi "um desabafo compartilhar o que vivi". Maria revela que muitas coisas ditas foram expressas pela primeira vez para alguém.

Principalmente nas entrevistas que ocorrem antes do tratamento oncológico, orienta-se a participação da criança ou do adolescente e dos familiares que estiverem presentes (pai, mãe, irmãos, avós, tios). Os pacientes entrevistados trazem a importância do apoio familiar para lidar com o adoecimento e, também, trazem queixas sobre a forma como são vistos pela família. Eles fazem referência à mãe, ao pai, à madrasta, ao padrasto, às tias, aos irmãos. No adoecimento oncológico, toda a família é atingida pela notícia e cada membro sofre uma certa perda de identidade, podendo ocorrer à centralização dessa identidade na pessoa deficiente (a irmã do menino surdo, a mãe do cego, o pai do aluno com paralisia etc.).

O processo de lidar com a perda (luto) precisa ser vivenciado por todos e não se restringem apenas ao medo da morte e à superação do ideal de ter um filho saudável. Mesmo em famílias harmônicas, a crise é inevitável. Cada membro vive a presença do doente de uma forma diferente, mas é muito comum a sobrecarga emocional e as tarefas de cuidado estar com a mãe da criança. As mulheres costumam interromper, inclusive, a vida profissional e/ou acadêmica e passam a viver em função do filho doente, o que implica em sofrimento emocional. A família (em muitos casos) costuma ter sua renda reduzida em razão da permanência da mulher em casa e das despesas aumentadas, já que os gastos com terapias e tratamentos específicos podem durar por quase toda a vida da criança.

Outra modalidade de atendimento pode se dar no espaço da brinquedoteca da instituição hospitalar. Considera-se que, geralmente, esses locais são atribuídos como de responsabilidade do psicopedagogo ou do voluntariado da instituição. Entretanto, defende-se que a brinquedoteca é um espaço privilegiado da prática psicanalítica em que as intervenções podem levar em conta as manifestações inconscientes.

Outra possibilidade são os grupos de pacientes sobreviventes, como uma modalidade de acolhimento com uma função terapêutica, na medida em que os participantes podem falar e ser ouvidos sobre os aspectos pessoais das suas experiências, comentando sobre suas dificuldades e os limites experienciados pelo seu corpo, podem partilhar angústias e preocupações em relação aos vínculos 
sociais, ouvindo, às vezes, a opinião de outros pacientes. Nesse sentido, pode ser um espaço onde circulem novas ideias, pois ao escutar outras experiências, pode suscitar que os sujeitos encontrem recursos para lidar com suas dificuldades. Entretanto, o psicanalista precisa ficar atento para o espaço compartilhado entre sujeitos, preservando aquilo que é próprio da psicanálise, que é abarcar a dimensão do sujeito em sua singularidade, evitando o efeito de massa quando os sujeitos borram suas diferenças ao identificar-se a um líder. Assim, é a ética, e não o setting analítico, que deve reger os atos do psicanalista. Os encontros podem ser mensais, abertos para as pessoas que queiram falar de sua experiência.

\section{Referências}

Almeida, M. D. (2017). Sobreviventes de câncer infanto-juvenil: Contribuições da Psicanálise e novos dispositivos clínicos. (Tese de doutorado, Instituto de Psicologia, Universidade de São Paulo, São Paulo). Recuperado de http://www.teses.usp.br/teses/disponiveis/47/47133/tde-25042017091726/en.php

Birman, J. (2014). Drogas, performance e psiquiatrização na contemporaneidade. Ágora: Estudos em Teoria Psicanalítica, 17 (spe), 2337. https://dx.doi.org/10.1590/S1516-14982014000300003

Birman, J. (2016, 08 de dezembro). Amor de si e amor do outro. Espaço Brasileiro de Estudos Psicanalíticos. Recuperado de https://www.youtube.com/watch?v=TaYWfbIye-Y

Brown, M., Levitt, G., Frey, E., Bárdi, E., Haupt, R., Hjorth, L. et al (2015, November). The Views of European Clinicians on Guidelines for LongTerm Follow-Up of Childhood Cancer Survivors. Pediatr Blood Cancer; 62 (2), $322 \quad-\quad-328 . \quad$ Recuperado de http://onlinelibrary.wiley.com/doi/10.1002/pbc.25310/epdf

Calligaris, C. (2006, 02 de fevereiro). Culpa e vergonha. Folha de São Paulo. Recuperado de www1.folha.uol.com.br/fsp/ilustrad/fq0202200622.htm

Contemporâneo (c2009 - 2018). In Dicionário online de português. Recuperado de https://www.dicio.com.br/contemporaneo/

Costa, J. (2012) Os sobrenomes da vergonha: melancolia e narcisismo. In: J. Verztman, R. Herzog, T. Pinheiro \& F. Pacheco-Ferreira (Orgs.). Sofrimentos narcísicos. (pp. 9-15). Rio de Janeiro: Cia de Freud: UFRJ; Brasília, DF: CAPES PRODOC. Recuperado de http://nepecc.psicologia.ufrj.br/files/livro_sofrimentosnarcisicos.pdf 
Debord, G. (1997). A sociedade do espetáculo: comentários sobre a sociedade do espetáculo. (E. Abreu, trad.) Rio de Janeiro: Contraponto.

Dunker, C. (2015, 08 de maio). Mal-estar, sofrimento e sintoma. Café Filosófico. Recuperado de https://vimeo.com/127741380.

Dunker, C. (2016, 22 de maio). Qual é a relação entre depressão e melancolia?. Falando nisso, $n$ n. $23 . \quad$ Recuperado de https://www.youtube.com/watch?v=41kGuYcG2eA

Elia, L. (2000). Psicanálise: clínica \& pesquisa. In: S. Alberti \& L. Elia (orgs.). Clínica e pesquisa em psicanálise. (pp. 19-36) Rio de janeiro: Rios Ambiciosos

Farah, B. (2012) Depressão e vergonha: contrafaces dos ideais de iniciativa e autonomia na contemporaneidade. In: J. Verztman, R. Herzog, T. Pinheiro \& F. Pacheco-Ferreira (Orgs.). Sofrimentos narcísicos. (pp. 185-206). Rio de Janeiro: Cia de Freud: UFRJ; Brasília, DF: CAPES PRODOC. Recuperado de http://nepecc.psicologia.ufrj.br/files/livro_sofrimentosnarcisicos.pdf

Fernandes, M. H. (2011) Corpo (4ª. ed., Coleção clínica psicanalítica) São Paulo: Casa do Psicólogo.

Freud, S. (1996). Sobre o narcisismo: uma introdução. In: Edição Standard Brasileira das Obras Psicológicas Completas de Sigmund Freud. (J. Salomão trad., vol. XIV, pp. 75-113) Rio de Janeiro: Imago (Trabalho original publicado em 1914)

Lacan, J. (1998) O estádio do espelho como formador da função do eu. In Escritos. (V. Ribeiro, trad.). Rio de Janeiro: Jorge Zahar Editora.

Laplanche, J. \& Pontalis, J. (2001). Narcisismo. In Vocabulário da Psicanálise. São Paulo: Martins Fontes.

Leclaire, S. (1977). Mata-se uma criança: um estudo sobre o narcisismo primário e a pulsão de morte. Rio de Janeiro: Zahar Editores

Magalhães, M. M. S. \& Azevedo, F. G. S.. (2016, Dezembro). A (de)pressão e a contemporaneidade: notas sobre o sintoma social. Revista Psicologia, Diversidade e Saúde. 5 (2), 215-226. doi: http://dx.doi.org/10.17267/23173394rpds.v5i2.1046

Pacheco-Ferreira, F. (2012) Algumas questões sobre a angústia e sua relação com a vergonha. In: J. Verztman, R. Herzog, T. Pinheiro \& F. PachecoFerreira (Orgs.). Sofrimentos narcísicos. (pp. 165-184). Rio de Janeiro: Cia 
de Freud: UFRJ; Brasília, DF: CAPES PRODOC. Recuperado de http://nepecc.psicologia.ufrj.br/wp-

content/uploads/2017/04/livro_sofrimentosnarcisicos.pdf.

Priszkulnik, L. (2011) O Corpo e as atividades físicas: contribuições da Psicanálise. In: E. S. N. Lange \& L. Tardivo. (Org.). Corpo, Alteridade e Sintoma: Diversidade e Compreensão. (1ª. ed., pp. 139-160) São Paulo: Vetor Editora Psicopedagógica Ltda.

Rosa, M. (2004, setembro). A pesquisa psicanalítica dos fenômenos sociais e políticos: metodologia e fundamentação teórica. Revista mal-estar e subjetividade - Fortaleza. IV (2), pp. 329-348

Venturi, C \& Vertman, J. (2012). Interseções da vergonha na cultura, na subjetividade e na clínica atual. In: J. Verztman, R. Herzog, T. Pinheiro \& F. Pacheco-Ferreira (Orgs.). Sofrimentos narcísicos. (pp. 119-147). Rio de Janeiro: Cia de Freud: UFRJ; Brasília, DF: CAPES PRODOC. Recuperado de http://nepecc.psicologia.ufrj.br/wpcontent/uploads/2017/04/livro_sofrimentosnarcisicos.pdf

Verdélio, A. (2016, 15 de fevereiro). Câncer infantil: taxa de cura no Brasil é a mesma há 30 anos. Agência Brasil. Recuperado de http://agenciabrasil.ebc.com.br/geral/noticia/2016-02/cancer-infantil-taxade-cura-no-brasil-e-mesma-ha-30-anos.

Zygouris, R. (1995). A vergonha de si. In: Ah! As belas lições! (C. Koltai, trad., pp. 159-172) São Paulo: Escuta. (Trabalho original publicado em 1988) 